\title{
The role of antibiotics in the prevention of preterm birth
}

\author{
Watson A Bowes $\mathrm{Jr}^{1,2}$
}

Addresses: ${ }^{1} 211$ Huntington Drive, Chapel Hill, NC 27514, USA; ${ }^{2}$ Division of Maternal Medicine, Department of Obstetrics \& Gynecology, University of North Carolina at Chapel Hill, 3010 Old Clinic, CB 7516, Chapel Hill, NC 27599-7516, USA

Email: wbowes@gmail.com

FI000 Medicine Reports 2009, I:22 (doi: 10.34I0/MI-22)

The electronic version of this article is the complete one and can be found at: http://FI000.com/Reports/Medicine/content/I/22

\begin{abstract}
There are multiple uses for antibiotics during pregnancy: treatment of intercurrent bacterial infections such as urinary or respiratory tract infections, maternal treatment to prevent fetal or neonatal disease, prophylactic treatment for surgical procedures, and treatment of puerperal infections. This report will summarize the current recommendations for the use of antibiotics specifically to reduce the risk of preterm birth.
\end{abstract}

\section{Introduction and context}

Preterm delivery, the leading cause of perinatal morbidity and mortality worldwide, occurs in $12-13 \%$ of births in the US and 5-9\% of births in many other developed countries [1]. Spontaneous preterm labor and preterm premature rupture of membranes together account for $80 \%$ of preterm births [2]. There is substantial evidence that infection and inflammatory mediators are implicated in the pathogenesis of preterm birth. Of all premature births, $25 \%$ or more occur in women with evidence of infection of the amniotic cavity [3]. Furthermore, proinflammatory cytokines, such as interleukin-1-beta and tumor necrosis factor-alpha, have been identified as mediators in the pathophysiology of preterm labor [4]. Specific maternal bacterial infections that have been shown to be associated with an increased risk of preterm birth include urinary tract infection [5], lower genital tract infection [6], and periodontal infection [7]. The specific pathophysiologic mechanisms by which these infections cause preterm birth include direct ascending infection of the placenta and fetus, transplacental blood-borne infection, and systemic activation of proinflammatory cytokines that activate prostaglandin production.

There is no controversy about the treatment of symptomatic bacterial infections during pregnancy, such as pyelonephritis, vaginitis, cervicitis, pneumococcal pneumonia, or listeriosis. A high index of clinical suspicion, the use of appropriate laboratory measures to confirm the diagnosis and identify the specific organism, and prompt treatment with appropriate antibiotics will reduce maternal morbidity, forestall preterm birth, and prevent fetal infections as in the case of listeriosis. What is controversial is the extent to which screening for and treatment of asymptomatic infection or antibiotic treatment of asymptomatic women at increased risk of preterm birth will reduce the risk of preterm birth or otherwise decrease perinatal morbidity.

In prescribing antibiotics (or any other drugs), for whatever indication, to women who are pregnant, physicians must keep in mind the potential untoward effect on the developing embryo and fetus. This is particularly important in the first 56 days of pregnancy, when the developing embryo is at the greatest risk of teratogenic effects of medications. If there is any doubt about the safety of a medication, a reliable reference should be consulted, such as that by Briggs et al. [8].

\section{Recent advances Asymptomatic bacteriuria}

Screening for and antibiotic treatment of asymptomatic bacteriuria during pregnancy are widely accepted as means of preventing pyelonephritis and reducing the risk 
of preterm birth [5]. The mechanism of action involved in the reduction of the risk of preterm birth is not entirely clear. Screening for bacteriuria in prenatal patients is advised. A meta-analysis by Devillé et al. [9], which included 70 studies, found the urine dipstick method of screening to be useful in excluding the presence of infection, especially in pregnant women. However, the rapid tests are less reliable in detecting infection and their use should not replace urine culture for detecting asymptomatic bacteriuria [9].

\section{Bacterial vaginosis}

Bacterial vaginosis (BV) is characterized by an overgrowth of a variety of anaerobic organisms, including Garderella vaginalis, Mycoplasma hominis, Mobiluncus species, Atopobium vaginae, and other organisms, and an associated reduction in normal vaginal Lactobacillus species [10]. A recent meta-analysis of 15 controlled trials, which included 5,888 women, found that antibiotic treatment was highly effective in eradicating BV in pregnancy [11]. However, a meta-analysis of seven recent randomized controlled trials of screening and treatment of pregnant women who were asymptomatic for BV evidence found that screening and treatment of pregnant women for BV did not result in a reduction in preterm birth. Also, there was concern about the potential for unintended harm from the treatment [12]. That study resulted in the recommendation by the US Preventive Services Task Force that current evidence is insufficient to support a policy of screening for BV in pregnant women at high risk for preterm delivery [13]. The use of probiotics (live organisms, especially Lactobacillus species) has been shown to be effective in treating BV, but evidence that probiotic treatment reduces the risk of preterm birth is lacking [14].

\section{Antibiotic treatment for patients in preterm labor}

Although the role of inflammation in the pathophysiology of spontaneous preterm birth is well documented, there is no evidence that the routine use of antibiotics in the management of patients with preterm labor has reduced the incidence of preterm birth. The most important study showing that lack of effectiveness of antibiotic therapy for preterm labor was the ORACLE II randomized controlled trial [15]. Women with intact membranes and in spontaneous premature labor $(\mathrm{n}=$ $6,295)$ were randomly assigned to treatment with various combinations of erythromycin, amoxicillin, and clavulanic acid and a placebo four times daily for 10 days. Although antibiotic treatment was associated with a lower occurrence of maternal infection, none of the antibiotic regimens were associated with a lower incidence of preterm birth. A meta-analysis by King and Flenady [16] of 11 controlled trials, which included the data from the ORACLE II trial, confirmed these findings. A follow-up study of 3,196 children from the ORACLE II trial at 7 years of age found that those who had received erythromycin either alone or in combination with amoxiclav were significantly more likely to have developed cerebral palsy [17]. In an evaluation of this study, Faculty of 1000 member Michael Marsh raised the possibility that the use of antibiotics might mask the signs of intrauterine infection thereby leading to the delayed delivery of an affected infant [18].

A recent meta-analysis of 17 controlled trials of the use of antibiotics in patients at risk of premature birth because of abnormal vaginal flora, previous preterm birth, or positive fetal fibronectin, found that there was no association between antibiotic treatment and reduction in preterm birth irrespective of the criteria used to assess risk, the antimicrobial agent administered, or gestational age at the time of treatment [19]. These data would be in accord with the recommendation of the American College of Obstetricians and Gynecologists (ACOG) that women in preterm labor should not be treated with antibiotics for the sole purpose of preventing preterm delivery [20].

At least two recent trials have found that preconception use of antibiotics to treat patients at increased risk of preterm birth has not been effective in reducing the subsequent risk of delivering a preterm infant for these patients, and in some instances, the treatment actually increased the risk of subsequent preterm birth $[21,22]$. In an evaluation of the study by Tita et al. [22], Faculty of 1000 member Bryan Larsen suggested that the destruction of bacteria by antibiotics may release toxic mediators leading to adverse outcomes or that the cause of preterm birth is more complex than has been suggested by research to date and will require a different set of measures applied to the intrauterine environment [23].

\section{Antibiotics in patients with preterm premature rupture of membranes}

The cause of preterm premature rupture of the membranes (PPROM), which occurs in 2 to $4 \%$ of all singleton pregnancies and in a higher proportion of twin pregnancies, is not known. Most cases of PPROM occur in otherwise healthy women without identifiable risk factors. However, ascending choriodecidual infection has been identified in some cases, although it is not known whether this is a cause or a consequence of PPROM. Nevertheless, the use of antibiotics in women with PPROM has been shown to increase the latency period, defined as the period between the rupture of membranes and the onset of labor. A meta-analysis by 
Ananth et al. [24] of nine placebo-controlled randomized trials of the use of antibiotics in patients with PPROM found a significant increase in the latency period and a reduction in neonatal sepsis in subjects who received antibiotic treatment as compared with those who received placebos. These studies suggested that broad-spectrum antibiotic coverage (for example, ampicillin-sulbactam) was more effective than a narrowspectrum antibiotic (ampicillin). Subsequent trials in patients with PPROM, including the trial conducted by the ORACLE Collaborative Group, have confirmed the efficacy of broad-spectrum antibiotic treatment in prolonging the latency period, prolonging gestation, and reducing the incidence of chorioamnionitis and of neonatal infection and intraventricular hemorrhage [25].

A number of different broad-spectrum antibiotic regimens have been used to treat patients with PPROM. Although there is no conclusive evidence demonstrating a single regimen that is superior, a 5-day course of antibiotic therapy including a macrolide (erythromycin or azithromycin) is effective [26].

The mechanism of action of the prolongation of the latency period achieved by antibiotic treatment of women with PPROM may be more complex than simply prevention of chorioamniotic infection. A recent study by Gomez et al. [27] analyzed two amniocentesis specimens taken 5 days apart in women with PPROM and found that antibiotic treatment (ceftriaxone, clindamycin, and erythromycin) failed to eradicate microbial invasion of the amniotic cavity or eliminate host inflammatory response. In an evaluation of this study, Faculty of 1000 member Austin Ugwumadu pointed out that the findings were consistent with existing evidence that antibiotics administered to the mother do not reach therapeutic levels within the fetal compartment to inhibit common pathogens [28].

Based on the information in two large multicenter clinical trials [29,30], ACOG recommends a 48-hour course of ampicillin and erythromycin followed by 5 days of amoxicillin and erythromycin during expectant management of PPROM remote from term to prolong pregnancy and to reduce infectious and gestational agedependent neonatal morbidity [31]. The use of ampicillin-clavulanic acid is not recommended because of its association with an increased rate of neonatal necrotizing enterocolitis [30]. Also, the ACOG recommendation notes that women with PPROM and who are known carriers of Group B Streptococcus, and those who give birth before carrier status can be delineated, should receive intrapartum prophylaxis (penicillin) to prevent vertical transmission regardless of earlier treatments. The guidelines of the Royal College of Obstetricians and Gynaecologists for the treatment of women with PPROM differ from those of the ACOG in the antibiotic regimen recommendation only: erythromycin (250 mg orally every 6 hours) for 10 days following the diagnosis of PPROM [32].

\section{Implications for clinical practice}

Screening for bacteriuria in prenatal patients is advised. However, rapid screening tests should not replace urine culture for detecting asymptomatic bacteriuria. Routine screening for and treatment of asymptomatic BV are not indicated. The use of antibiotics to treat women at high risk of preterm birth or those with idiopathic spontaneous preterm labor does not significantly decrease the incidence of preterm birth and may result in an increased risk of neonatal developmental abnormalities. This does not preclude the need for prophylaxis against early-onset Group B streptococcal disease when indicated. Patients with preterm premature rupture of membranes should receive a 7 - to 10-day course of antibiotic therapy. Antibiotic regimens should include a macrolide (erythromycin or azithromycin) but not ampicillinclavulanic acid.

\section{Abbreviations}

ACOG, American College of Obstetricians and Gynecologists; $\mathrm{BV}$, bacterial vaginosis; PPROM, preterm premature rupture of the membranes.

\section{Competing interests}

The author declares that he has no competing interests.

\section{References}

I. Goldenberg RL, Culhane JF, lams JD, Romero R: Epidemiology and causes of preterm birth. Lancet 2008, 37I:75-84.

2. Menon R, Fortunato SJ: Infection and the role of inflammation in preterm premature rupture of the membranes. Best Pract Res Clin Obstet Gynaecol 2007, 21 :467-78.

3. Romero R, Gotsch F, Pineles B, Kusanovic JP: Inflammation in pregnancy: its role in reproductive physiology, obstetrical complications, and fetal injury. Nutr Rev 2007, 65:SI94-202.

4. Christiaens I, Zaragoza DB, Guilbert L, Robertson SA, Mitchell BF, Olson DM: Inflammatory processes in preterm and term parturition. J Reprod Immunol 2008, 79:50-7.

5. Smaill F: Asymptomatic bacteruria in pregnancy. Best Pract Res Clin Obstet Gynaecol 2007, 21 :439-50.

6. Swadpanich $U$, Lumbiganon $P$, Prasertcharoensook W, Laopaiboon $M$ : Antenatal lower genital tract infection screening and treatment programs for preventing preterm labor. Cochrane Database Syst Rev 2008, (2):CD006I78.

7. Lin D, Moss K, Beck JD, Hefti A, Offenbacher S: Persistently high levels of periodontal pathogens associated with preterm pregnancy outcomes. J Periodontol 2007, 78:833-4I.

8. Briggs GG, Freeman RK, Yaffe SJ: Drugs in Pregnancy and Lactation: A Reference Guide to Fetal and Neonatal Risk. Philadelphia: Lippincott Williams \& Wilkins; 2008. 
9. Devillé WL, Yzermans JC, van Duijn NP, Bezemer PD, van der Windt DA, Bouter LM: The urine dipstick test useful to rule out infections. A meta-analysis of the accuracy. BMC Urol 2004, 4:4 [http://www.biomedcentral.com/I47I-2490/4/4].

10. Fredricks, DN, Fiedler TL, Marrazzo JM: Molecular identification of bacteria associated with bacterial vaginosis. $N$ Engl J Med 2005, 353:1886-7.

FI000 Factor 9.0 Exceptional

Evaluated by Matthias Maiwald 4 May 2006

I I. McDonald HM, Brocklehurst P, Gordon A: Antibiotics for treating bacterial vaginosis in pregnancy. Cochrane Database Syst Rev 2007, (I):CD000262.

12. Nygren P, Fu R, Freeman M, Bougatsos C, Klebanoff M, Guise JM; U.S. Preventive Services Task Force: Evidence on the benefits and harms of screening and treating pregnant women who are asymptomatic for bacterial vaginosis: an update review for the U.S. Preventive Services Task Force. Ann Intern Med 2008, | 48:220-33.

13. U.S. Preventive Services Task Force: Screening for bacterial vaginosis in pregnancy to prevent preterm delivery: U.S. Preventive Services Task Force recommendation statement. Ann Intern Med 2008, I48:214-9.

14. Othman M, Neilson JP, Alfirevic Z: Probiotics for preventing preterm labour. Cochrane Database Syst Rev 2007, (I):CD00594I.

FI000 Factor 3.0 Recommended

Evaluated by Bryan Larsen 25 Nov 2008

15. Kenyon SL, Taylor DJ, Tarnow-Mordi W, ORACLE Collaborative Group: Broad-spectrum antibiotic for spontaneous preterm labour, the ORACLE II randomized trial. ORACLE Collaborative Group. Lancet 200I, 357:989-94.

16. King J, Flenady V: Prophylactic antibiotics for inhibiting preterm labour with intact membranes. Cochrane Database Syst Rev 2002, (4):CD000246.

17. Kenyon S, Pike K, Jones DR, Brocklehurst P, Marlow N, Salt A, Taylor DJ: Childhood outcomes after prescription of antibiotics to pregnant women with spontaneous preterm labour: 7-year follow-up of the ORACLE II trial. Lancet 2008, 372:1319-27.

Changes Clinical Practice

FI000 Factor 4.8 Must Read

Evaluated by Michael Marsh 7 Oct 2008, John Wyatt 13 Nov 2008

18. Marsh M: Evaluation of: Kenyon S, Pike K, Jones DR, Brocklehurst P, Marlow N, Salt A, Taylor DJ. Childhood outcomes after prescription of antibiotics to pregnant women with spontaneous preterm labour: 7-year follow-up of the ORACLE II trial. Lancet 2008, 372:13 | 9-27. Faculty of 1000 Medicine. 2008 Oct 7. [http://www.fl000medicine.com/article/id/ I I 23076]

19. Simcox R, Sin WT, Seed PT, Briley A, Shennan AH: Prophylactic antibiotics for the prevention of preterm birth in women at risk: a meta-analysis. Aust N Z J Obstet Gynaecol 2007, 47:368-77.

20. ACOG Committee on Practice Bulletins. American College of Obstetricians and Gynecologist: ACOG Practice Bulletin. Clinical management guidelines for obstetrician-gynecologist. Number 43, May 2003. Management of preterm labor. Obstet Gynecol 2003, 101:1039-47.

21. Andrews WW, Goldenberg RL, Hauth JC, Cliver SP, Copper R, Conner $M$ : Interconceptional antibiotics to prevent spontaneous preterm birth: a randomized clinical trial. Am J Obstet Gynecol 2006, 194:6I7-23.

22. Tita AT, Cliver SP, Goepfert AR, Conner M, Goldenberg RL, Hauth JC, Andrews WW: Clinical trial of interconception antibiotics to prevent preterm birth: subgroup analysis and possible adverse antibiotic-microbial interaction. Am J Obstet Gynecol 2007, 197:367.el-6.

FI000 Factor 3.2 Recommended

Evaluated by Torsten Reinheimer 26 Nov 2007, Bryan Larsen 20 Dec 2007

23. Larsen B: Evaluation of: Tita AT, Cliver SP, Goepfert AR, Conner M, Goldenberg RL, Hauth JC, Andrews WW. Clinical trial of interconceptional antibiotics to prevent preterm birth: subgroup analyses and possible adverse antibioticmicrobial interaction. Am J Obstet Gynecol 2007, 197:367.el-6. Faculty of 1000 Medicine. 2007 Dec 20. [http://www.fl000medicine. com/article/id//097087]

24. Ananth CV, Guise J-M, Thorp JM Jr.: Utility of antibiotic therapy in preterm premature rupture of membranes: a metaanalysis. Obstet Gynecol Surv 1996, 5 I:324-8.

25. Kenyon S, Bolvain M, Neilson J: Antibiotics for preterm rupture of membranes: a systematic review. Obstet Gynecol 2004, 104: 1051-7.

26. Caughey $A B$, Robinson JN, Norwitz ER: Contemporary diagnosis and management of preterm premature rupture of membranes. Rev Obstet Gynecol 2008, I:I I-22.

27. Gomez R, Romero R, Nien JK, Medina L, Carstens M, Kim YM, Espinoza J, Chaiworapongsa T, Gonzalez R, lams JD, Rojas I: Antibiotic administration to patients with pre term premature rupture of membranes does not eradicate intraamniotic infection. J Matern Fetal Neonatal Med 2007, 20:I67-73.

FI000 Factor 6.0 Must Read

Evaluated by Austin Ugwumadu 26 Jul 2007

28. Ugwumadu A: Evaluation of: Gomez R, Romero R, Nien JK, Medina L, Carstens M, Kim YM, Espinoza J, Chaiworapongsa T, Gonzalez R, lams JD, Rojas I: Antibiotic administration to patients with pre term premature rupture of membranes does not eradicate intra-amniotic infection. I Matern Fetal Neonatal Med 2007, 20: 167-73. Faculty of 1000 Medicine. 2007 Jul 26. [http://www.fl 000medicine.com/article/id/I08774I/evaluation]

29. Mercer BM, Miodovnik M, Thurnau GR, Goldenberg RL, Das AF, Ramsey RD, Rabello YA, Meis PJ, Moawad AH, lams JD, Van Dorsten JP, Paul RH, Bottoms SF, Merenstein G, Thom EA, Roberts JM, McNellis D: Antibiotic therapy for reduction of infant morbidity after preterm premature rupture of the membranes. A randomized controlled trial. National Institute of Child Health and Human Development Maternal-Fetal Medicine Units Network. JAMA 1997, 278:989-95.

30. Kenyon S, Taylor DJ, Tarnow-Mordi W: Broad spectrum antibiotics for preterm, prelabor rupture of fetal membranes: the ORACLE I randomized trial. ORACLE Collaborative Group. Lancet 200I, 357:979-88.

31. ACOG Committee on Practice Bulletins-Obstetrics: ACOG Practice Bulletin No. 80: premature rupture of membranes. Clinical management guidelines for obstetrician-gynecologists. Obstet Gynecol 2007, 109:1007-19.

32. Royal College of Obstetricians and Gynaecologists: Preterm Prelabour Rupture of Membranes, Guideline No. 44 (November 2006) http://www.rcog.org.uk/index.asp?PagelD=1813 